\title{
BEST CONSTANT OF THE CRITICAL HARDY-LERAY INEQUALITY FOR CURL-FREE FIELDS IN TWO DIMENSIONS
}

\author{
NAOKI HAMAMOTO AND FUTOSHI TAKAHASHI*
}

Abstract. In this note, we prove that the best-possible constant of the critical Hardy-Leray inequality for curl-free fields is $1 / 4$, just the same value as the one for all smooth fields. This fact contrasts sharply with the recent result on the subcritical Hardy-Leray inequality for curl-free fields by the authors [6], and shows the criticality of the inequality.

Mathematics subject classification (2010): Primary 26D10; Secondary 35A23.

Keywords and phrases: Critical Hardy-Leray inequality, curl-free vector fields, the best constant.

\section{REFERENCES}

[1] O. Costin, AND V. MAZ'YA, Sharp Hardy-Leray inequality for axisymmetric divergence-free fields, Calculus of Variations and Partial Diff. Eq., 32 (2008), no. 4, 523-532.

[2] N. Намамото, Sharp Rellich-Leray inequality for axisymmetric divergence-free vector fields, Calc. Var. Partial Differential Equations, 58, (2019), no. 4, Art. 149, 23 pp.

[3] N. Hамамото, Three-dimensional sharp Hardy-Leray inequality for solenoidal fields, Nonlinear Anal. 191, (2020), 111634, 14 pp.

[4] N. НАмамото, Sharp Hardy-Leray inequality for solenoidal fields, OCAMI Preprint Series 2020, http://www.sci.osaka-cu.ac.jp/OCAMI/publication/preprint/preprint.html.

[5] N. HAмамото, AND F. TAKAHASHI, Sharp Hardy-Leray inequality for three-dimensional solenoidal fields with axisymmetric swirl, Commun. Pure Appl. Anal., 19, no. 6, (2020), 3209-3222.

[6] N. Hamamoto, AND F. TAKAHASHI, Sharp Hardy-Leray and Rellich-Leray inequalities for curlfree vector fields, Math. Ann. (2021), no. 1-2, 719-742.

[7] N. Hamamoto, AND F. TAKAHASHI, Sharp Hardy-Leray inequality for curl-free fields with a remainder term, J. Funct. Anal., 280, no. 1, (2021), 108790.

[8] O. A. LAdYZHENSKAYA, The mathematical theory of viscous incompressible flow, Second edition, revised and enlarged, Mathematics and its Applications, Vol. 2 Gordon and Breach, Science Publishers, New York-London-Paris, (1969).

[9] J. LERAY, Étude de diverses équations intégrales non linéaires et de quelques problèmes que pose l'hydrodynamique, J. Math. Pures Appl., 12, 1933. 1-82.

[10] A. I. NAZARov, AND N. Ustinov, A generalization of the Hardy inequalitiy, J. Math. Sci (N. Y.), 244 (2020), no. 6, 998-1002.

[11] F. TAKAHASHI, A simple proof of Hardy's inequality in a limiting case, Arch. Math. 104 (2015), $77-82$. 